\title{
Musikstipendien in der Schweiz für Kinder und Jugendliche mit einer Behinderung
}

Musique Espérance Schweiz, Mitglied einer nichtstaatlichen Organisation unter der Schirmherrschaft der UNESCO, arbeitet seit 1983 in unserem Land und hat sich zum Ziel gesetzt, die Musik in den Dienst der Menschenrechte, des Friedens und der Jugend zu stellen.

In Zusammenarbeit mit der Schweizerischen Chorvereinigung wurde eine Aktion für Kinder und Jugendliche mit einer Behinderung ins Leben gerufen: Einrichtung eines Fonds für Studienbeträge von 3000 bis 5000 Franken für Beiträge zur Anschaffung eines Musikinstrumentes und als Kostenübernahme für Musikunterricht während zwei Jahren.
Der berühmte blinde Musiker Ray Charles aus den USA wird am 17. Februar 2000 in der Arena von Genf ein ausserordentliches Konzert geben, dessen Reingewinn für die Finanzierung dieser Aktion bestimmt ist.

Sollten Sie Kinder und Jugendliche mit einer Behinderung kennen, welche durch ein solches Stipendium Gelegenheit bekämen, ein Instrument $\mathrm{zu}$ erlernen, dann nehmen Sie bitte Kontakt auf mit Antoine Nussbaumer Dr. med., Postfach 1226, 1870 Monthey 2. Tel. 02447112 64, Fax 02447211 41, E-mail: a.nussbaumer@bluewin.ch.

\section{Bourses d'études musicales en faveur de jeunes handicapés}

Musique Espérance Suisse, une ONG établie en Suisse depuis 1983, a pour objectif de mettre la musique en service des Droits de l'Homme, de la Jeunesse et de la Paix.

En partenariat avec l'Union Suisse des Chorales, elle lance une action en faveur de jeunes handicapés habitant la Suisse: créer des bourses d'études musicales de 3000 à 5000 francs couvrant l'achat d'un instrument et les frais de cours pendant deux ans.
Dans le même but, le célèbre chanteur noir aveugle, Ray Charles, donnera un concert exceptionnel à l'Aréna de Genève le 17 février 2000, dont le bénéfice intégral reviendra à cette action.

Si vous connaissez un jeune handicapé qui, grâce à une telle bourse, pourrait apprendre à jouer d'un instrument de musique, prenez contact à l'adresse suivante: Antoine Nussbaumer chirurgien, C. P. 1226, 1870 Monthey 2, tél. 02447112 64, fax 02447211 41, e-mail a.nussbaumer@bluewin.ch. 